\title{
restorative justice and women in vanuatu
}

\author{
Rita Naviti \\ Former Registrar of the Supreme Court and the \\ Court of Appeal of Vanuatu, questions the capacity \\ for restorative justice endeavours to be effective in \\ Vanuatu's male-dominated society
}

\section{Background}

When I was approached to make a contribution to this conference on restorative justice in relation to women, I immediately said: 'I will think about it'. It was an indirect way of saying, 'What is it?' I spent the next two days thinking about it and went through a few books that I have on justice, and found NOTHING! What could it be? I had to get more information from someone who knows of justice beyond Vanuatu and, perhaps, the region.

The person I consulted laughed and said: 'Ah! RESTORATIVE JUSTICE ... new concepts where parties to cases or conflicts get together and try to fix things to do justice to everyone involved...'. Before he could complete the explanation, I added: 'Oh! A kind of ADR ... those bright new ideas that come out of developed countries'. There was not enough on this topic for me to give a talk on. Had the organiser not called me, I would have pretended that I had forgotten all about it and avoided being embarrassed today. On the other hand it would have been an opportunity missed if no-one attempted to speak out about the feelings, the fears and the hopes of women in a forum like this. 


\section{Introduction}

'Restorative justice' is new in Vanuatu's official vocabulary, but not new in its meaning and application to this part of the world. It has been used in resolving problems in our society for decades, using custom law as the basis for restoring justice. These customary decisions were practical and implemented without question.

Be reminded that in those days problem solving was the business of the senior men of the village chosen by the chief, and usually named the council. Their meetings were held in a nakamal (house where men drink kava). Where I come from women were not allowed to participate. If they were allowed in, it was for the great council to obtain more information on a specific problem involving the woman.

It might be interesting to note that in those days women did not worry about their well-being or that of their children. The society took care of them. They were always submitting themselves and bearing the consequences of any decisions that may have affected their lives. They had no hobbies, nor time for themselves. They had no notion of money. All they valued was the happy impression of a husband when he showed satisfaction with the way his pigs were cared for. Pigs were the value of a husband's assets. Unlike wives, pigs had names.

\section{The fears}

In a male dominated society such as ours women are easily intimidated. It would be unwise to use the concept of restoring justice in a conflict between individuals where there is a power imbalance between the parties. Its practical implementation would also be difficult. Sometimes justice might be restored at the cost of a dissatisfied woman. Is that justice truly restored?

As women have usually been peacemakers they could voluntarily give up discussion and/or negotiation for the sake of having peace restored. Will that result in reciprocal justice? Will that benefit a woman victim of conflict? How can these questions be answered? Let us look at the context of Vanuatu, both past and present. Five decades ago it was the father who 
chose his daughter's husband. Two decades ago girls were the property of their fathers. Consequently sexual abuse has increased and defendants are allowed to get away with no criminal liability. Today the 'bride price' arrangements are still obligatory. By comparison with how boys are treated our attitude towards girls is still undermining them.

Many women today pay the price of that practice. They silently accept the prejudices directed against them. Take for example the dissolution of marriage cases in which women get the decree of dissolution to be free from an unhappy marriage. Consider that after ten years or so of marriage the unemployed wife is divorced and sent away to start her new life with nothing. In my view there is no justice in such cases. Or take the case when an unhappy wife leaves home. Because she was paid the bride price, the children of her marriage who love her belong to her husband. She has to leave home without them. Or consider a wife who is convinced that she cannot leave home because she was paid for.

'Restorative justice' is a good concept, but it needs careful analysis before it is introduced. It is my view that Vanuatu women of today will legitimately have reservations about its capacity to restore justice in legal cases today. How can justice be restored when the mediators are all men who use ideas that favour men?

\section{The hopes}

Since Independence our Constitution has provided for equal rights, duties and responsibilities for men and women. The word 'gender' is coming into increasing usage in public offices. The Gender Equity Department was introduced. It represents the equity component of the Government's Comprehensive Reform Program. So women, using the Constitution as their basis and foundation, have emerged and have gained the attention of leaders and governors and have achieved recognition as well as finding their proper place in society today.

Having said that, do the majority of women fully understand the concept of restorative justice in order to 
positively use it? Where the notion of 'family ties' is strong, and the members of society are close to each other, the concept should not be discouraged. It could reduce damage and injustice caused to needy and incapable children who generally fall victim to the selfish behaviour of adults and which leads to broken homes. Used well it can make justice faster, less expensive, more creative and able to address the underlying interests of all parties.

As far as our young are concerned I think that they know more than we think. They see the world differently and should handle the concept more easily. Therefore I hope that its precepts will be practised, but not before women are able to play a full part.

In a country where there is so much ethnic, cultural, customary and traditional diversity, restorative justice would be useful in providing fair resolution to conflicts involving groups of people in communities and/or in cases of national social unrest. Then people would obey the chiefs rather than be arrested by the police and end up in the criminal justice system. Such experience was put to the test during the Vanuatu National Provident Fund riot in Port Vila in 1998 and during social unrest in two communities in Luganville last year.

In all conflicts and particularly those of national importance, the concept of 'restorative justice' cannot function properly without the participation of women. Women and children are usually the first victims of a conflict; 'restorative justice' should accommodate their participation and women should be prepared to assist in negotiations. In this kind of conflict resolution the role of women in the process is vital. 'She', being the symbol of love, peace and reconciliations can bring vital qualities as opposed to men who have preferred to use the law of Moses, 'an eye for an eye' and 'a tooth for a tooth'. 


\section{Conclusion}

The South Pacific islands are our untouched paradise where custom, tradition and culture are still alive in this new millennium in 80 per cent of our islands. On the other hand, the system has failed in situations where the Constitution is not allowed to rule and the adopted legal system cannot find its proper place. With the high cost of justice, the delay and the lack of resources in our justice system today, it would be wise to use restorative justice. I am supported in this view by the Domestic Protection Bill of 1999 which intends to restore power to chiefs to make Temporary Protection Orders and to attempt to restore peace between parties.

I heard and agreed with some friends who expressed the failure of the courts of law as, 'Law orders, Custom reconciles'. Restorative justice would be best used if it could combine customary justice with the normal legal justice system so that its decisions should not only restore peace and harmony but also restore justice, in other words if it could both 'reconcile' and 'order'.

I suggest this new concept can only properly serve our litigants with the involvement of women. But it will need proper research and analysis of the current system, taking into account this period where women have just emerged and, most importantly, the education of our men and children on gender issues. 